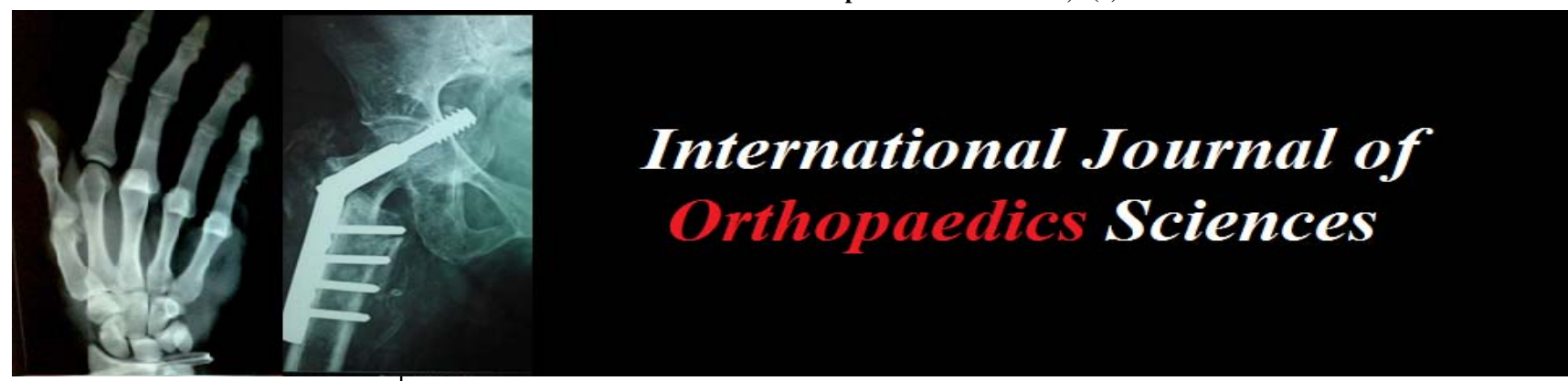

ISSN: $2395-1958$

IJOS 2017; 3(1): 109-110

(C) 2017 IJOS

www.orthopaper.com

Received: 19-11-2016

Accepted: 20-12-2016

Dr. Shyam Srinivasan

MD Pediatrics, Senior Resident,

Grant Government Medical

College, Mumbai, India

Dr. Devanand Gulab Chaudhari MD Pediatrics, Lecturer, Grant Government Medical College,

Mumbai, India

Dr. MD Sabri Ahsan

Junior Resident (Pediatrics),

Grant Government Medical

College, Mumbai, India

Dr. Prachi Atmapoojya Junior Resident (Pediatrics),

Grant Government Medical

College, Mumbai, India

Dr. Yugesh Kumar Agarwal Junior Resident (Pediatrics) Grant Government Medical College, Mumbai, India
Correspondence Dr. Shyam Srinivasan MD Pediatrics, Senior Resident, Grant Government Medical College, Mumbai, India

\section{A rare case of Fibrodysplasia ossificans progressive}

\author{
Dr. Shyam Srinivasan, Dr. Devanand Gulab Chaudhari, Dr. MD Sabri \\ Ahsan, Dr. Prachi Atmapoojya and Dr. Yugesh Kumar Agarwal
}

DOI: $\underline{\text { http://dx.doi.org/10.22271/ortho.2017.v3.i1b.19 }}$

\section{Abstract}

Fibrodysplasia ossificans progressiva (FOP), a rare and disabling genetic condition characterized by congenital malformations of the great toes and progressive heterotopic endochondral ossification (HEO) which is the most catastrophic of HEO disorders in humans. We hereby report a case of FOP in a 3 year old female child with multiple HEO and genetically confirmed missense variation of exon 6 of the ACVR1 gene.

Keywords: Fibrodysplasia ossificans progressiva, heterotopic endochondral ossification, ACVR1 gene

\section{Introduction \\ 1.1 Case Report}

Our patient was a 3 year old girl who presented with complaints of multiple swellings over the back, fore head and neck on and off since 2 months of age, which used to disappear by themselves without treatment. When the child came to us she had restricted neck movements, hard, well defined, non-tender swellings on forehead, neck and sacrum.

MRI cervical spine done on 2014 showed hyperintense ill-defined signal in the muscular plane on right side of the neck. A repeat MRI and CT spine at our centre showed extensive intramuscular and subcutaneous calcifications extending along the entire length of the spine, bilaterally. X ray foot showed valgus deformity of the great toes. Histopathology of biopsy specimen from the cervical region showed fibrocartilaginous tissue. A genetic analysis was done which showed heterozygous missense variation in exon 6 of the ACVR1 gene (chr2:158630626; C $>$ C/T; Depth: 165x) that results in amino acid substitution of Histidine for Arginine at codon 206(p.R206H; ENST00000263640).

\section{Discussion}

Fibrodysplasia ossificans progressiva is a rare disease involving progressive ossification of skeletal muscle, fascia, tendons and ligaments. FOP has a prevalence of approximately 1 in 2 million, and shows no geographic, ethnic, racial, or gender preference. Most cases are sporadic and dominant inheritance is supported by observations of 2 or 3 successive generations affected and the finding of a paternal age effect in sporadic cases ${ }^{[1]}$. The average age at the onset of ossification was five years. Children appear normal at birth except for great toe abnormalities (short, deviated, and monophalangic). Heterotopic ossification occurs progressively over the course of a lifetime in a direction that was axial to appendicular, cranial to caudal, and proximal to distal; this pattern appeared typical for fibrodysplasia ossificans progressive ${ }^{[2]}$ with most patients being confined to a wheelchair by the third decade of life and requiring lifelong care ${ }^{[3]}$. Malformations of the great toes and progressive heterotopic endochondral ossification (HEO) are the characteristic anatomic patterns. During the first decade of life, most children with FOP develop episodic, painful inflammatory soft tissue swellings.

While some flare-ups regress spontaneously, most transform soft connective tissues including aponeuroses, fascia, ligaments, tendons, and skeletal muscles into mature heterotopic bone. Minor trauma such as intramuscular immunizations, mandibular blocks for dental work, muscle fatigue, blunt muscle trauma from bumps, bruises, falls, or influenza-like viral illnesses 
can trigger painful new flare-ups of FOP leading to progressive heterotopic ossification ${ }^{[4]}$. Surgical removal of heterotopic bone provokes explosive and painful new bone growth. Smith et al. (1996) reviewed FOP on 28 patients and found that ossification in the large skeletal muscles began from birth to 16 years (mean age 4.6 years), involving the neck and upper spinal muscles, and later around the hips, major joints, and jaw. Delay in diagnosis was mainly due to failure to recognize the abnormal toes, which were recognizable at birth in all cases. Radiographic changes were observable in the cervical spine and the metaphyses of the long bones [5]. Clinical suspicion of FOP early in life on the basis of malformed great toes can lead to early clinical diagnosis, and the avoidance of additional harmful diagnostic and treatment procedures ${ }^{[6]}$.

In April 2006, an international team of researchers found that FOP is caused by a mutation of a gene on chromosome 2 (2q23-24) for a receptor in the BMP signaling pathway called ACVR1. Classic FOP is caused by a recurrent activating mutation $(617 \mathrm{G}>\mathrm{A} ; \mathrm{R} 206 \mathrm{H})$ in the gene ACVR1/ALK2 encoding Activin A receptor type I/Activin-like kinase 2, a bone morphogenetic protein (BMP) type I receptor. BMP receptors help determine the fate of the stem cells in which they are expressed. Classic FOP occurs when a particular amino acid in the ACVR1 protein is substituted for another amino acid at a specific location. Atypical FOP patients also have heterozygous ACVR1 missense mutations in conserved amino acids [7]. Shore et al. (2006) conducted a linkage analysis using a subset of 5 families with the most stringent and unambiguous features of FOP, congenital malformation of the great toes and progressive heterotopic ossification were found to be the characteristic anatomic patterns in all affected patients. This approach identified linkage of FOP to chromosome 2q23-q24, a genetic interval including the ACVR1 gene ${ }^{[8]}$.

\section{Points to Remember}

Deformity of the great toe and HEO are the clinical pointers in the early suspicion and diagnosis of FOP.

\section{References}

1. Tuente W, Becker PE, Von Knorre GV, Zur Genetik der. Myositis ossificans progressiva. Humangenetik 1967; 4:320-351.

2. Cohen RB, Hahn GV, Tabas JA, Peeper J, Levitz CL, Sando A et al. The natural history of heterotopic ossification in patients who have fibrodysplasia ossificans progressiva. A study of forty-four patients. J Bone Joint Surg Am. 1993; 75(2):215-9

3. Petrie KA, Lee WH, Bullock AN, Pointon JJ, Smith R, Russell RGG et al. Novel Mutations in ACVR1 Result in Atypical Features in Two Fibrodysplasia Ossificans Progressiva Patients. PLoS ONE 2009; 4(3):e5005. doi:10.1371/journal.pone.0005005.

4. Kaplan FS, Le Merrer M, Glaser DL, Pignolo RJ, Goldsby RE, Kitterman JA et al. Fibrodysplasia ossificans progressiva. Best Pract Res Clin Rheumatol. 2008; 22:191-205.

5. Smith R, Athanasou NA, Vipond SE. Fibrodysplasia (myositis) ossificans progressiva: clinicopathological features and natural history. Quart. J Med. 1996; 89:445456,

6. Kaplan FS, Xu M, Glaser DL, Collins F, Connor M, Kitterman $\mathrm{J}$ et al. Early diagnosis of fibrodysplasia ossificans. Progressive Pediatrics. 2008; 121(5):e1295-
300.

7. Pignolo RJ, Shore EM, Kaplan FS. Fibrodysplasia ossificans progressiva: clinical and genetic aspects. Orphanet J Rare Dis. 2011; 1(6):80.

8. Shore EM, Xu M, Feldman GJ, Fenstermacher DA, Cho TJ, Choi IH et al. A recurrent mutation in the BMP type I receptor ACVR1 causes inherited and sporadic fibrodysplasia ossificans progressiva. Nature Genet. 38: 525-527, Note: Erratum: Nature Genet. 2006; 39:276 only, 2007. 